\title{
Estado, empresariado e variedades de capitalismo no Brasil: política de internacionalização de empresas privadas no governo Lula
}

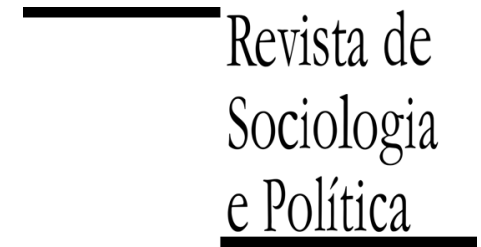

DOI 10.1590/1678-987314225105

\author{
Danilo Rocha
}

\begin{abstract}
RESUMO
O artigo analisa a economia política do processo de internacionalização de empresas privadas brasileiras ocorrido durante o governo Lula (2003-2010). A partir de 2005, verificou-se uma expansão do investimento direto brasileiro no exterior, resultado de uma política do governo federal destinada a formar grandes empresas transnacionais capazes de concorrer internacionalmente. Grandes fusões, aquisições e projetos de investimentos no exterior foram financiados por recursos públicos, no âmbito da política industrial operada pelo Banco Nacional de Desenvolvimento Econômico e Social (BNDES), principal banco estatal de fomento ao setor privado no país. Uma característica importante desse movimento foi a concentração em setores nos quais o Brasil já é competitivo, como os intensivos em trabalho e recursos naturais, em contradição com diretrizes originalmente estabelecidas pela própria política industrial do governo Lula, que preconizava o incentivo a indústrias mais intensivas em tecnologia. A partir da análise empírica de casos de internacionalização, argumenta-se que isso ocorreu porque a política pautou-se por demandas de curto prazo de grupos econômicos privados. Utilizando a abordagem institucional das "variedades de capitalismo", conclui-se que a ação do BNDES foi path dependent, no sentido de que dependeu de projetos de viabilidade imediata. Depreende-se do resultado que características institucionais mais gerais da economia brasileira deixam a política industrial do governo federal sujeitas a demandas de curto prazo do setor privado.
\end{abstract}

PALAVRAS-CHAVE: internacionalização de empresas; política industrial; BNDES; variedades de capitalismo; empresariado.

Recebido em 28 de Maiode 2012. Aprovado em 27 de Maio de 2013.

\section{I - Introdução ${ }^{1}$}

${ }^{1}$ Agradeço aos pareceristas anônimos da Revista de Sociologia e Politica por seus comentários e contribuições a este artigo.

${ }^{2}$ De acordo com a série medida pelo Instituto Brasileiro de Geografia e Estatística (IBGE), até 2011. A propósito de comparação, destaque-se que a taxa de crescimento do PIB nos anos 1990 foi de $1,7 \%$ ao ano, ao passo que na segunda metade dos anos 2000 a média foi de $5,14 \%$.

\footnotetext{
${ }^{3}$ Dados sobre investimento direto estrangeiro foram colhidos dos relatórios da Conferência das Nações Unidas para o Comércio e Desenvolvimento (UNCTAD 2011a; 2011b).
}

$\mathrm{E}$ $\mathrm{m}$ meio às maiores taxas de crescimento do Produto Interno Bruto (PIB) em mais de duas décadas ${ }^{2}$, a economia brasileira convive, nos últimos anos, com uma novidade importante: a expansão do investimento direto no exterior, decorrente da crescente internacionalização de suas empresas. A economia fechada, de reduzida inserção internacional, deu lugar a um processo de abertura cada vez mais acentuado, materializado em fluxos comerciais, atração de capitais estrangeiros e, ultimamente, ascensão de firmas transnacionais de controle nacional. Desde a liberalização comercial e financeira, no início dos anos 1990, algumas empresas, estatais ou privadas, começaram a adquirir ativos e estabelecer operações produtivas em outros países em volume mais significativo. Em 1995, o estoque de investimento brasileiro no exterior era de US\$ 44,4 bilhões. Em 2010, chegou a aproximadamente US\$ 181 bilhões, constituindo um aumento de mais de 300\%. Em termos de participação no Produto Interno Bruto do país, o percentual passou de 5\% para 9\% no período, representando uma parcela crescente da renda nacional ${ }^{3}$.

A partir de 2005, no final do primeiro mandato do governo Lula, essa tendência aprofundou-se, consolidando um processo de internacionalização produtiva de capitais brasileiros, como fica evidente no Gráfico 1 (Gammeltoft 2008; Gammeltoft, Pradhan \& Goldstein 2010; Hiratuka \& Sarti 2011). Além 
Gráfico 1 - Investimento direto brasileiro no exterior (US\$ milhões)

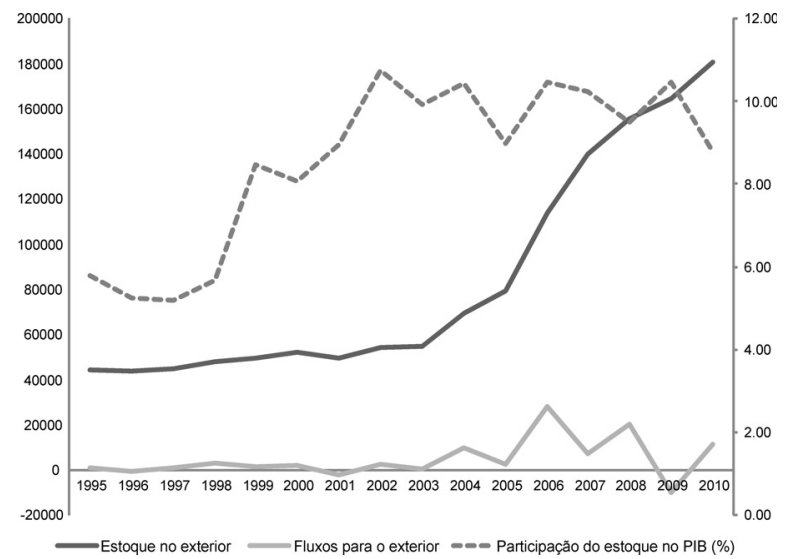

Fonte: UNCTAD (2012).

de empresas estatais, como Petrobras, firmas de controle privado também participaram com destaque desse movimento - e são os casos privados o objeto do presente estudo. Apesar de o investimento direto brasileiro no exterior (IDE) ser ainda muito baixo em relação ao total que circula na economia global, diversas empresas do país ganharam importância internacional ${ }^{4}$. Algumas passaram a constar na lista das maiores transnacionais do mundo, além de consolidarem-se como atores influentes da vida nacional. Trata-se um fenômeno importante e de amplo impacto na estrutura do país, que deve ser estudado não apenas em sua dimensão econômica, mas também política. A necessidade de proteção e expansão de investimentos brasileiros no exterior é uma questão que mobiliza atores e grupos de interesse empresariais em busca de melhoria na posição relativa de seus negócios, demandando atuação do Estado, seja ela direta, seja em forma de regulação. A alta especificidade de ativos vinculados a IDE é crucial para essa relação estreita com o poder político. A impossibilidade de reverterem-se gastos em capacidade produtiva no exterior rapidamente e sem perdas relevantes faz com que Estados nacionais engajem-se em negociações e ações internacionais em benefício dos proprietários desses ativos (Büthe \& Milner 2008). Além disso, é preciso considerar os interesses do próprio Estado, que, em tese, pode instrumentalizar a internacionalização de capitais nacionais tanto para fortalecer seu poder internamente junto ao empresariado local, quanto para posicionar-se de maneira mais incisiva no cenário internacional, caracterizando-se como ação de política externa (Flynn 2007). Veja-se, por exemplo, no Gráfico 1, a evolução do investimento direto brasileiro no exterior.

O sentido de "internacionalização produtiva" em questão não se restringe, portanto, à exportação de bens produzidos em plantas nacionais. Refere-se a uma categoria mais avançada, que envolve compra e/ou criação de atividade produtiva no exterior por meio de investimento direto. A partir desse mecanismo, a firma associa suas operações a mercados de outros países e regiões, passando a atuar de forma internacionalizada. $\mathrm{O}$ investimento direto estrangeiro concretiza-se de diversas formas, tais como representações comerciais e plataformas logísticas no exterior, construção de plantas industriais em outros países (greenfield investment) e aquisição de ativos de empresas estrangeiras. Desse modo, uma firma internacionalizada integra-se à economia global e concorre nos mercados internacionais. Ela adapta-se, em nível global, a padrões estratégicos e operacionais existentes em sua área de atuação. Transforma-se em empresa transnacional (ETN), ganhando poder de mercado, capacidade de concorrer internacionalmente e importância econômica (Dunning 1988; Hennart 2001). 
A forte participação do Estado foi uma característica importante no recente movimento de formação de empresas transnacionais privadas brasileiras, que ganhou força a partir de 2005. A internacionalização produtiva de grupos econômicos nacionais durante a gestão Lula fez parte das diretrizes da política industrial do governo federal, operada, entre outras agências, pelo Banco Nacional de Desenvolvimento Econômico e Social (BNDES), principal banco estatal de fomento ao setor privado no Brasil. Tratou-se de uma política pública estruturada, concebida no domínio da estratégia governamental de desenvolvimento produtivo do país, resultando em casos de expansão do investimento direto brasileiro no exterior induzidos pelo poder público. Essa constatação torna oportuna uma análise da economia política desse processo, trazendo à luz atores e interesses que condicionaram a tomada de decisão de investimentos brasileiros em outros países. Emprega-se essa abordagem neste estudo, destacando-se as relações entre Estado e empresariado, interesses envolvidos e instituições em que essas interações ocorreram.

Um pressuposto a ser considerado é a independência desses casos de internacionalização produtiva em relação a condicionantes políticos externos. Assim, rejeitam-se explicações como a tese do "subimperialismo brasileiro", segundo a qual a exportação de capitais nacionais seria sintoma do expansionismo de uma potência intermediária em direção a suas áreas de influência, sobretudo a América do Sul. Investimentos diretos fluiriam para essa região em razão do reduzido mercado consumidor brasileiro, o que por sua vez decorreria da superexploração da mão-de-obra local por empresas transnacionais originárias de países centrais. Nesse caso, a política de internacionalização estaria estreitamente ligada às diretrizes da política externa do país (Marini 1972; Luce 2007). Da mesma maneira, não se subscreve a teoria do "capitalismo global", de acordo com a qual a internacionalização seria resultado de decisões de uma classe capitalista global descolada dos Estados nacionais, formada por executivos de empresas transnacionais, grandes investidores internacionais, burocracia de instituições multilaterais e políticos de países desenvolvidos (Sklair 2002a; 2002b; Robinson 2004).

Para Flynn (2007), a tese do subimperialismo brasileiro sugere uma relação causal "mecanicista" entre restrições no mercado consumidor interno e expansionismo de firmas nacionais, o que não se verifica na realidade. Já a teoria do capitalismo global, de acordo com o mesmo autor, tem pouco poder explicativo porque minimiza a importância dos Estados nacionais em decisões de investimentos, o que também carece de evidência empírica. Nesse sentido, o presente artigo procura explicar a recente onda de internacionalização de empresas nacionais pela dinâmica política interna brasileira. Sustenta-se que, além de ser uma decisão autônoma do país, não está ligada à política externa. Trata-se, primordialmente, de um desdobramento da política industrial, cujo objetivo é a expansão de empresas e setores econômicos, sem se ocupar com a inserção do país no sistema internacional.

A questão em análise diz respeito à influência de fatores políticos na fase de execução da política industrial do governo federal. Durante a gestão Lula, o processo de internacionalização de empresas privadas induzido pelo Estado tendeu a favorecer o empresariado de setores nos quais o Brasil já é competitivo, como o de construção civil e os intensivos em trabalho e recursos naturais. Paradoxalmente, a mesma política industrial preconizava, em sua fase de formulação, o apoio a setores mais intensivos em tecnologia, cuja falta de competitividade e déficit na balança comercial persistem na economia brasileira. Qual a razão desse descompasso? Neste artigo, argumenta-se que o processo de internacionalização de empresas pautou-se por demandas de curto prazo de grupos privados por recursos da política industrial. Sem mecanismos institucionais capazes de estabelecer acordos coletivos de longo prazo entre Estado e 
empresariado, a política industrial brasileira tornou-se dependente de projetos viáveis no curto prazo. Para fundamentar o argumento, buscam-se conceitos delineados pela literatura sobre "variedades de capitalismo", cuja abordagem, baseada em path dependence (dependência da trajetória) e na complementaridade dos arranjos institucionais das diferentes economias de mercado, ajuda a explicar resultados de políticas de desenvolvimento (Hall \& Soskice 2001; Schneider 2008). Mostra-se, desse modo, que a internacionalização de empresas apoiada pelo Estado refletiu características institucionais mais gerais da economia brasileira, como o formato da estrutura de representação coletiva de interesses empresariais e seu papel no estabelecimento de acordos coletivos entre Estado e empresariado (Schneider 2009).

A Tabela 1 lista os casos de fusões, aquisições e investimentos no exterior de empresas privadas ocorridos com apoio do BNDES durante o governo Lula, por meio de financiamento ou compra de participação acionária por meio da BNDES Participações (BNDESPAR), subsidiária do banco. Algumas empresas, como Gerdau e Vale, já apresentavam um elevado grau de internacionalização anteriormente, e figuravam entre as maiores empresas transnacionais brasileiras. Outras, como JBS-Friboi e Marfrig, do setor de frigoríficos, eram menos internacionalizadas, mas em poucos anos transformaram-se em empresas transnacionais com grande presença no mercado mundial.

$\mathrm{O}$ artigo prossegue com uma discussão sobre a atuação do empresariado como ator político no Brasil, definindo-se a forma de sua interação com o Estado e outros atores políticos à luz de conceitos trazidos pela literatura sobre variedades de capitalismo. Posteriormente, delineiam-se as diretrizes da política industrial do governo Lula, destacando-se o papel institucional do BNDES em sua fase de execução. Depois, apresenta-se um breve histórico da internacionalização de empresas brasileiras desde a abertura econômica, nos anos 1990, culminando nos casos mais recentes. Por fim, estuda-se os casos de internacionalização da JBS-Friboi, empresa do setor de frigoríficos, e da Fibria, do setor de celulose, cuja ascensão internacional nos últimos anos foi expressiva.

\section{II - Estado, empresariado e variedades de capitalismo no Brasil}

O processo de internacionalização de empresas induzido pelo Estado enseja a questão da atuação do empresariado como ator político no Brasil. É relevante discutir de que maneira a classe empresarial age coletivamente em defesa de seus interesses, como ocorre a articulação política dentro e entre setores, e como caracteriza-se sua interação com o poder público e outros atores políticos, como sindicatos de trabalhadores. Existe uma ampla literatura que trata do tema, dando corpo a um debate tradicional nas Ciências Sociais do país. A discussão remonta à década de 1950, na esteira do debate sobre a força política do empresariado nacional. À época, discutia-se se o grande empresariado industrial doméstico seria capaz de liderar um processo de modernização da economia brasileira, agindo de maneira a prevalecer sobre interesses resistentes a um projeto de desenvolvimento de caráter mais nacionalista - sobretudo os interesses ligados ao latifúndio e ao capital estrangeiro. Em aliança com os trabalhadores urbanos, a classe empresarial imporia suas preferências sobre outros dois atores influentes da política nacional - as elites agrária e burocrático-militar (Mancuso 2007).

Enquanto nos anos 1950 autores como Hélio Jaguaribe e Nelson Werneck Sodré (apud Mancuso 2007) acreditavam na força política do empresariado brasileiro, nos anos 1960 havia uma descrença em relação à capacidade da classe industrial de agir coletivamente e fazer prevalecer seus interesses. Autores como Fernando Henrique Cardoso e Celso Furtado consideravam o empresariado um ator político fraco, que pouco confrontava os interesses da elite 
Tabela 1 - Casos de internacionalização de empresas com apoio do BNDES no governo Lula

\begin{tabular}{|c|c|c|c|c|c|}
\hline Empresa & Setor & $\begin{array}{c}\text { Principais fusões e } \\
\text { aquisições }\end{array}$ & País & Ano & Participação do BNDES \\
\hline \multirow[t]{6}{*}{ Bertin } & \multirow[t]{6}{*}{ Alimentício } & Canelones & Uruguai & 2006 & $\begin{array}{l}\text { Financiamento e compra de } \\
\text { participação acionária }(26,9 \%)\end{array}$ \\
\hline & & Quality Meat & Paraguai & 2006 & \\
\hline & & Couros Trump & China & 2006 & \\
\hline & & Vigor & Brasil & 2007 & \\
\hline & & Rigamonti & Itália & 2008 & \\
\hline & & JBS-Friboi & Brasil & 2009 & \\
\hline \multirow[t]{3}{*}{ Braskem } & \multirow[t]{3}{*}{ Petroquímico } & Ipiranga & Brasil & 2007 & $\begin{array}{l}\text { Financiamento e compra de } \\
\text { participação acionária }(5,5 \%)\end{array}$ \\
\hline & & Sunoco Chemicals & EUA & 2010 & \\
\hline & & Quattor & Brasil & 2010 & \\
\hline \multirow[t]{2}{*}{ Brasil Foods } & \multirow[t]{2}{*}{ Alimentício } & Sadia & Brasil & 2009 & Financiamento \\
\hline & & Perdigão & Brasil & 2009 & \\
\hline \multirow{3}{*}{$\begin{array}{l}\text { Camargo } \\
\text { Corrêa }\end{array}$} & \multirow[t]{3}{*}{ Construção civil } & Loma Negra & Argentina & 2005 & Financiamento \\
\hline & & Ancap & Uruguai & 2007 & \\
\hline & & Cimpor Cimentos & Portugal & 2010 & \\
\hline \multirow[t]{2}{*}{ Fibria } & \multirow[t]{2}{*}{ Celulose } & $\mathrm{VCP}$ & Brasil & 2009 & $\begin{array}{l}\text { Financiamento e compra de } \\
\text { participação acionária }(30,42 \%)\end{array}$ \\
\hline & & Aracruz & Brasil & 2009 & \\
\hline \multirow[t]{6}{*}{ Gerdau } & \multirow[t]{6}{*}{ Siderurgia } & SiderPeru & Peru & 2006 & $\begin{array}{l}\text { Financiamento e compra de } \\
\text { participação acionária }(3,4 \%)\end{array}$ \\
\hline & & Chaparral Steel & EUA & 2007 & \\
\hline & & Qanex Corp & EUA & 2007 & \\
\hline & & Sidenor & Espanha & 2008 & \\
\hline & & Macsteel & EUA & 2008 & \\
\hline & & Ameristeel & Canadá & 2010 & \\
\hline \multirow[t]{5}{*}{ JBS-Friboi } & \multirow[t]{5}{*}{ Alimentício } & Swift Armour & Argentina & 2005 & $\begin{array}{l}\text { Financiamento e compra de } \\
\text { participação acionária }(30,41 \%)\end{array}$ \\
\hline & & Swift Foods & EUA & 2007 & \\
\hline & & Smithfield & EUA & 2008 & \\
\hline & & Pilgrims Pride & EUA & 2009 & \\
\hline & & Bertin & Brasil & 2009 & \\
\hline \multirow[t]{10}{*}{ Marfrig } & \multirow[t]{10}{*}{ Alimentício } & $\begin{array}{l}\text { Breeders and Packers } \\
\qquad(\mathrm{AB} \& \mathrm{P})\end{array}$ & Argentina & 2006 & $\begin{array}{l}\text { Financiamento e compra de } \\
\text { participação acionária }(13,89 \%)\end{array}$ \\
\hline & & Quinto Cuarto (50\%) & Chile & 2006 & \\
\hline & & Tacuarembó & Uruguai & 2006 & \\
\hline & & Inaler & Uruguai & 2006 & \\
\hline & & Carroll's Food do Brasil & EUA & 2008 & \\
\hline & & CDB Meats & Reino Unido & 2008 & \\
\hline & & OSI & EUA & 2008 & \\
\hline & & Seara (Cargill) & EUA & 2009 & \\
\hline & & Keystone Foods & EUA & 2010 & \\
\hline & & O'Kane Poultry & Reino Unido & 2010 & \\
\hline
\end{tabular}


Tabela 1 - cont.

\begin{tabular}{|c|c|c|c|c|c|}
\hline Empresa & Setor & $\begin{array}{c}\text { Principais fusões e } \\
\text { aquisições }\end{array}$ & País & Ano & Participação do BNDES \\
\hline \multirow[t]{2}{*}{ Odebrecht } & Construção civil & $\begin{array}{l}\text { Odebrecht América Latina } \\
\text { e Angola }\end{array}$ & AL e Angola & 2006 & Financiamento \\
\hline & & Odebrecht Venezuela & Venezuela & 2009 & \\
\hline \multirow[t]{3}{*}{ Perdigão } & Alimentício & Batávia & Brasil & 2006 & Financiamento \\
\hline & & Plusfood & Holanda & 2007 & \\
\hline & & Eleva & Argentina & 2008 & \\
\hline \multirow[t]{3}{*}{ Sadia } & Alimentício & Big Foods & Brasil & 2007 & Financiamento \\
\hline & & Excelsior & Brasil & 2008 & \\
\hline & & Goiaves & Brasil & 2008 & \\
\hline \multirow[t]{5}{*}{ Vale } & Mineração & Inco & Canadá & 2006 & $\begin{array}{l}\text { Financiamento e compra de } \\
\text { participação acionária }(5,4 \%)\end{array}$ \\
\hline & & AMCI Holdings & Austrália & 2007 & \\
\hline & & Rio Tinto (ativos) & Reino Unido & 2009 & \\
\hline & & Cementos Argos & Colômbia & 2009 & \\
\hline & & BSG Resources Guinea & Reino Unido & 2010 & \\
\hline \multirow{3}{*}{$\begin{array}{l}\text { Votorantim } \\
\text { Cimentos }\end{array}$} & Cimentos & Cemex & EUA & 2005 & Financiamento \\
\hline & & Acerías Paz del Rio & Colômbia & 2007 & \\
\hline & & Cementos Avellaneda & Argentina & 2009 & \\
\hline \multirow{5}{*}{$\begin{array}{l}\text { Votorantim } \\
\text { Metais }\end{array}$} & Siderurgia & Acerias Paz del Rio & Colômbia & 2007 & Financiamento \\
\hline & & AcerBag & Argentina & 2007 & \\
\hline & & US Zinc & EUA & 2008 & \\
\hline & & Cia Minera Atacocha & Peru & 2008 & \\
\hline & & Cía Minera Milpo SAA & Peru & 2010 & \\
\hline
\end{tabular}

Fonte: o autor. Tabela elaborada pelo autor a partir de informações extraídas de diversas fontes, como sites do BNDES, das empresas citadas e da Bolsa de Valores de São Paulo (Bovespa), relatórios aos investidores e dados sobre operações diretas disponibilizadas pelo BNDES e BNDESPAR.

agrária e do capital estrangeiro (Cardoso 1972; Furtado 1965). Satisfazia-se apenas em ser sócio minoritário de uma aliança envolvendo Estado e capital internacional, ratificada pelo golpe militar de 1964. Porém, no final dos anos 1970 e início dos anos 1980, a percepção sobre a classe mudou novamente entre estudiosos do tema, entre os quais Velasco e Cruz, Renato Boschi e Eli Diniz (apud Mancuso 2007). A recorrente participação do empresariado nos eventos políticos mais importantes do país até então seriam indício do vigor da classe, fato reforçado por sua adesão às campanhas de desestatização e democratização nos anos 80 (Mancuso 2007).

O debate sobre as relações entre Estado e empresariado prossegue até o presente, ajudando a explicar resultados de políticas públicas envolvendo atores empresariais no Brasil. De um lado, alguns trabalhos (Schneider 2002; 2004; Power \& Doctor 2002) defendem a tese da debilidade política do empresariado brasileiro. Atribui-se essa fragilidade ao sistema corporativista estatal de representação de interesses, cuja fragmentação inviabilizaria uma ação coletiva eficaz. Porém, essa posição é confrontada por pesquisas que atestam a capacidade de mobilização da classe empresarial nacional. Utilizando dados empíricos sobre a tramitação de leis no Congresso Nacional entre 1996 e 2003, 
Mancuso (2004) mostra a eficiência da ação coletiva empresarial na implantação de uma agenda destinada a reduzir o chamado "Custo Brasil", cujas medidas referentes a tópicos como redução da carga tributária e flexibilização de leis trabalhistas estavam em estreita consonância com os interesses da indústria. Na mesma linha, Oliveira (2003) destaca a mobilização empresarial para as negociações da Área de Livre Comércio das Américas (ALCA), nos anos 1990. O mais notável é que essas mobilizações ocorreram sob a liderança da Confederação Nacional da Indústria (CNI), a entidade de cúpula do corporativismo brasileiro, indicando vigor do sistema de representação coletiva dos interesses empresariais nas relações com o parlamento e em negociações internacionais (Mancuso \& Oliveira 2006). Além disso, trabalhos de Renato Boschi e Eli Diniz reforçam a ideia de força política do empresariado nacional, que continuou a mostrar habilidade na defesa de seus interesses durante as reformas liberais na década de 1990 e também durante o governo Lula, com o recrudescimento da participação do Estado na economia. Esses estudos ressaltam a diversidade de canais de representação cultivados pelos empresários, o que indica forte ativismo político do segmento (Diniz \& Boschi 2004; Diniz 2010a).

Evidenciada a força do empresariado brasileiro como ator político, cabe analisar a atuação dessa classe no âmbito da política industrial, e como sua interação com instituições próprias da economia brasileira influenciam os resultados das políticas governamentais de incentivo ao setor privado. Essa abordagem remete à literatura sobre "variedades de capitalismo", que identifica diferentes combinações institucionais existentes nos distintos países capitalistas e relaciona-as a determinadas formas de organização econômica. Cada arranjo institucional tem impacto em questões como padrão de inovação tecnológica das firmas, nível de qualificação e especialização da mão-de-obra, abrangência da proteção social estatal e desempenho econômico ao longo do tempo (Hall \& Soskice 2001; Jackson \& Deeg 2006; Bohle \& Greskovits 2009).

Levam-se em consideração instituições formais e informais que coordenam a ação dos agentes presentes em uma economia de mercado. O agente central é a firma, que interage estrategicamente com trabalhadores, consumidores, acionistas e atores estatais. Cinco dimensões institucionais básicas entram na análise: governança corporativa e finanças, relações interindustriais (dentro e entre setoriais, além de relações com fornecedores e consumidores), sistema de educação e treinamento da mão-de-obra, relações com os trabalhadores e relações industriais (o que inclui a forma de representação coletiva de interesses empresariais e sua relação com sindicatos e governos). Elas formam uma estrutura que condiciona a estratégia dos agentes, gerando padrões específicos de ação econômica em cada ambiente institucional, com resultados igualmente específicos. Um conceito importante subjacente a essa abordagem é o de complementaridade institucional, segundo o qual uma instituição aumenta seu desempenho na presença de outra, ainda que isso não leve necessariamente a um equilíbrio ótimo. Outro conceito relevante é o de path dependence (dependência da trajetória), que associa características institucionais de hoje a decisões tomadas em conjunturas críticas do passado, decisões que sofrem mudanças graduais e condicionadas pelo tempo (Hall \& Soskice 2001; Jackson \& Deeg 2006).

Cada país possui combinações institucionais próprias, e identificam-se dois tipos básicos de capitalismo: economias liberais de mercado, cujos representantes mais destacados são Estados Unidos e Reino Unido, e economias coordenadas de mercado, cujos principais exemplos são Alemanha e Japão. O primeiro grupo apresenta instituições que favorecem mecanismos de mercado nas transações entre os agentes econômicos, ao passo que as instituições existentes nas economias coordenadas permitem soluções mais negociadas e de longo prazo. No entanto, essa tipologia pode ser adaptada e expandida para 
5 O principal exemplo de agências semi-públicas de treinamento de mão-de-obra são aquelas que formam o chamado "sistema S", como Senai, Sesi, Senar e Senac, cujo custeio é divido entre governo e entidades de representação patronal. outros casos. O Brasil apresenta elementos institucionais tanto do modelo liberal quanto do coordenado, mas seu regime produtivo adquire forma própria. Para Schneider (2009), o capitalismo brasileiro, assim como a maioria dos países latino-americanos, é uma economia hierárquica de mercado, na qual relações de hierarquia sobrepujam tanto a coordenação quanto mecanismos de mercado. No Brasil, os atores dominantes da economia são grandes grupos econômicos diversificados - que, junto com corporações multinacionais, controlam o acesso a capital, tecnologia e mercados (idem). Na governança corporativa, o controle desses grupos é concentrado e predominantemente familiar, de modo que gerentes e demais stakeholders são pouco autônomos em relação a controladores majoritários. Nas relações interindustriais, características como diversificação das atividades dos grupos em subsidiárias, presença de oligopólios e uso de integração vertical dificultam a coordenação e as relações de mercado, favorecendo a hierarquia. As relações trabalhistas também apresentam traços de hierarquia. A representação sindical é reduzida e pouco eficaz, os vínculos entre empregado e empregador são atomizados e a rotatividade no emprego é alta, resultando em baixo poder de barganha dos trabalhadores e relação desigual em favor dos empregadores (Schneider 2008; 2009; Schneider \& Soskice 2009). Do mesmo modo, o sistema de qualificação de mão-de-obra pouco favorece o treinamento avançado nas empresas, sendo o Estado responsável pela educação genérica e agências semipúblicas ${ }^{5}$ responsáveis pelo treinamento profissional básico (Delgado et al., 2010, p. 974). Em geral, as maiores vantagens competitivas da economia brasileira residem em setores intensivos em recursos naturais e mão-de-obra, como agroindústria, minérios, proteína animal, além de produtos industriais "commoditizados", como autopeças e têxteis, nos quais a diferenciação por marca é reduzida (Schneider 2008).

Nas relações industriais, o Brasil caracteriza-se por uma variedade de canais de representação de interesses, sejam eles corporativistas, sejam pluralistas, formando um sistema complexo e fragmentado (Diniz 2010a; 2010b). O sistema corporativista tem peso importante na ação coletiva da classe empresarial, como ficou claro na mobilização pela redução do "Custo Brasil" no Congresso Nacional e nas negociações da ALCA (Mancuso \& Oliveira 2006). No campo da política industrial em análise, porém, as instituições de representação de interesses coletivos não exercem uma função de articulação política significativa. A política industrial brasileira - considerada aquela operada pelo BNDES - não conta com um aparato institucional que viabilize a coordenação entre empresas, setores e Estado, prescindindo de um instrumento importante das modernas políticas industriais (Delgado et al., 2010, p. 971 e 978). Não existem arenas de negociação coletiva em que se estabelecem contrapartidas, metas e ganhos conjuntos de longo prazo entre os diferentes atores envolvidos no ciclo dessa política pública (idem). Os incentivos financeiros estatais a empresas privadas sujeitam-se a demandas de curto prazo, caracterizando uma situação de path dependence no processo de alocação de recursos da política industrial. Desse modo, a tendência é a reprodução das relações de hierarquias características do capitalismo brasileiro, com predomínio de interesses de grupos econômicos já competitivos, cujos projetos de investimentos são mais viáveis e estruturados no curto prazo (Diniz 2010a; 2010b; Delgado 2008; Delgado et al., 2010). O Quadro 1 resume as principais características institucionais do capitalismo brasileiro segundo a abordagem das "variedades de capitalismo".

\section{III - A política industrial e o BNDES}

Políticas industriais são consideradas, sobretudo para países em desenvolvimento, instrumentos de catching up tecnológico e aumento da produtividade 
Quadro 1 - Características institucionais do capitalismo brasileiro

\begin{tabular}{ll}
\hline Dimensão institucional & Características \\
\hline $\begin{array}{l}\text { Governança corporativa e } \\
\text { finanças }\end{array}$ & Controle concentrado e familiar \\
& Financiamento de bancos estatais e autofinanciamento \\
& Gerência definida pelos controladores principais \\
Relações interindustriais & Oligopólios nas relações intrasetoriais \\
& $\begin{array}{l}\text { Relações inter-setoriais via grupos econômicos } \\
\text { diversificados }\end{array}$ \\
& Integração vertical nas relações com fornecedores \\
Educação e treinamento de & Estado fornece educação genérica \\
mão-de-obra & Órgãos semi-públicos fornecem educação técnica \\
básica & Pouco treinamento avançado nas empresas \\
& Organização sindical corporativa \\
Relações com & Baixa sindicalização \\
trabalhadores & Vínculos atomizados, com alta rotatividade \\
& Representação de interesses empresariais complexa e \\
fragmentada & Canais corporativistas e pluralistas, com baixa \\
coordenação & Política industrial sem contrapartida \\
\hline
\end{tabular}

Fontes: Schneider (2008) e Delgado et al. (2010).

dos fatores de produção das economias nacionais. Trata-se de uma ação de amplo escopo, envolvendo medidas cujo objetivo é minimizar falhas de mercado e problemas de coordenação que impedem o desenvolvimento de determinados setores industriais e, consequentemente, da economia como um todo. Suas atividades abrangem campos heterogêneos, demandando a atuação do governo em diversas áreas, como comércio exterior, tributação, crédito e treinamento de mão-de-obra. Em tese, os principais objetivos e prioridades da política industrial dependem de decisões políticas baseadas no chamado "interesse nacional". O aumento da produtividade da economia e sua inserção competitiva no mercado internacional seriam bens públicos suficientemente importantes para a mobilização de recursos públicos em benefício da classe empresarial, sem desencadear conflitos distributivos. Nos países em desenvolvimento, essa discussão ganha mais importância, pois, além da questão econômica e produtiva, convivem com problemas de distribuição de renda desigual e pobreza acentuada (Suzigan \& Furtado 2006; Delgado et al., 2010; Robinson 2009).

As políticas industriais dividem-se em horizontais e verticais. Economistas ortodoxos são, em geral, mais favoráveis a políticas horizontais. Elas são setorialmente neutras e concentram as ações governamentais na melhoria do ambiente de negócios para todas as empresas e setores da economia, sem escolher os "vencedores". Em contrapartida, o receituário heterodoxo sugere uma política industrial vertical baseada na escolha clara de indústrias e setores estratégicos, não impondo restrições para que, quando necessário, apenas uma firma de determinado setor receba incentivos. Baseada na economia evolucionária neoschumpeteriana, essa corrente preconiza a inovação como causa pri- 
mordial do desenvolvimento, em um processo em que tecnologias, instituições, setores e firmas evoluem de forma conjunta e complementar. Sem negar a importância de políticas horizontais, recomenda-se que, principalmente nos países em desenvolvimento, a participação do Estado seja ativa, no sentido de promover-se rápido e sustentável aumento da produtividade da economia por meio de incentivos diretos a cadeias produtivas incompletas e sem perspectivas de desenvolver-se autonomamente. Nesse sentido, o estabelecimento de políticas setoriais para indústrias intensivas em tecnologia seria uma maneira de países atrasados alcançarem o nível de produtividade de países ricos para concorrerem em condições de igualdade no mercado internacional. Sem isso, não seriam possíveis ganhos significativos de salários e receitas tributárias no longo prazo. De acordo com essa visão, o processo de criação de novas tecnologias e aprendizado das existentes deve ser capitaneado pelo Estado por meio da política industrial, que mobilizaria recursos e instituições para prover um bem público de interesse nacional - o que inclui a escolha dos "vencedores". Caso contrário, o catching up tecnológico não se daria pelas livres forças do mercado (Suzigan \& Furtado 2006; 2010).

No Brasil, o Estado opera tanto políticas industriais horizontais quanto verticais. As políticas horizontais são mais disseminadas e envolvem uma miríade de ações e instituições, em várias áreas governamentais. Destacam-se nesse caso as chamadas "reformas microeconômicas" destinadas a melhorar o ambiente de negócios de empresas nos mais diversos setores, definidas sem um propósito de desenvolvimento de cadeias produtivas específicas definidas ex ante pelo Estado. Políticas horizontais não são exclusivas do governo federal, mas praticadas também por Estados e municípios (Delgado 2008). No entanto, o enfoque deste trabalho é a política industrial vertical do governo Lula, sob a qual se promoveu a internacionalização de empresas nos últimos anos. Um dos principais instrumentos dessa política são os desembolsos do BNDES, cuja concessão depende de uma decisão ex ante do governo, destinada a alcançar objetivos localizados de desenvolvimento industrial. Além de financiamento direto a projetos, o BNDES auxilia empresas por meio de compra de participação acionária e aquisição de títulos de dívida privados (debêntures). As duas últimas funções são desempenhadas pela BNDES Participações (BNDESPAR), subsidiária responsável pela gestão de participações do banco (Suzigan \& Furtado 2010). A importância desses recursos para o setor privado é reforçada pelo fato de o Brasil não contar com um mercado de capitais privado desenvolvido o suficiente para financiar projetos de longo prazo em condições tão favoráveis quanto as proporcionadas pelo BNDES, cujas taxas de juros praticadas (Taxa de Juros de Longo Prazo - TJLP) são, em parte, subsidiadas pelo Tesouro Nacional (Rabelo \& Simões 2010).

A concepção de política industrial vertical ganhou força na gestão Lula a partir de 2004, com o lançamento da Política Industrial, Tecnológica e de Comércio Exterior (PITCE) (Brasil 2004) pelo Ministério da Indústria, Desenvolvimento e Comércio Exterior, após anos de predomínio de políticas horizontais. Ainda que nesse programa continuassem a constar medidas de melhoria do ambiente de negócios, tornou-se evidente a disposição do governo federal de privilegiar alguns setores da economia considerados estratégicos para o desenvolvimento econômico de longo prazo. Fazendo jus à orientação neoschumpeteriana, definiram-se como prioritários setores intensivos em tecnologia, como semicondutores, fármacos e medicamentos, softwares e bens de capital. Preconizava-se ainda o estímulo a "setores portadores do futuro", como a biotecnologia e a nanotecnologia. Em 2008, o governo iniciou uma nova fase da política industrial, com o lançamento da Política de Desenvolvimento Produtivo (PDP) (Brasil 2008). Apesar de o número de setores atendidos ter sido ampliado, permaneceu, na fase de formulação, o foco na 
${ }^{6}$ Dados disponíveis em Banco Central do Brasil (2008;

2010). inovação e na promoção de atividades tecnologicamente dinâmicas (Delgado 2010, p. 994).

A importância do BNDES para a política industrial, sobretudo no segundo mandato do governo Lula, pode ser medida pelo volume de recursos desembolsados pela instituição durante o período (ver Gráfico 2). A partir de 2007, o Tesouro Nacional começou a conceder empréstimos cada vez maiores ao banco, fortalecendo sua capacidade de financiamento. Até 2010, o valor total repassado foi de $\mathrm{R} \$ 451$ bilhões $^{6}$, evidenciando o peso da instituição na economia brasileira. Além disso, o Tesouro dobrou sua parte no capital social da empresa, que passou para R $\$ 30$ bilhões (BNDES 2010a). Isso aumentou ainda mais seu poder de captação e desembolso. A partir da crise internacional de 2008, tornou-se também um importante instrumento da política fiscal anticíclica do governo federal, o que significou expansão ainda maior de suas atividades. Em 2010, o desembolso do banco ficou em R $\$ 168,4$ bilhões, ao passo que em 2003, primeiro ano do governo Lula, foi de $\mathrm{R} \$ 35,1$ bilhões, representando uma variação de 379\% (BNDES 2007; 2010b). Uma variável importante a ser considerada é o desenho institucional do BNDES. Por se tratar de uma empresa pública, e não de um órgão da administração direta, o banco tem autonomia para tomar decisões de investimentos sem passar pelo escrutínio do parlamento e outros órgãos de controle. Assim, o poder Executivo é soberano no desembolso dos recursos, que não fazem parte do orçamento federal.

\section{IV - Histórico do investimento direto brasileiro no exterior}

${ }^{7}$ Estatísticas sobre o IDE brasileiro no exterior podem ser encontradas em Banco Central do Brasil (2006).
Mesmo considerando-se apenas os países em desenvolvimento, o IDE brasileiro sempre foi baixo em relação ao resto do mundo. Essa característica era acentuada pelo modelo de desenvolvimento autárquico, baseado em substituição de importações. No momento subsequente à abertura econômica empreendida no início dos anos 1990, os atores mais importantes do processo de internacionalização de companhias brasileiras foram aqueles ligados a atividades financeiras, como bancos, fundos de investimentos e seguradoras. Esses capitais destinavam-se, sobretudo, a paraísos fiscais, aproveitando as oportunidades oferecidas pela liberalização para buscar novas formas de valorização e proteção (Prochnik 2009). Ainda hoje, a maior parte dos capitais brasileiros no exterior provém do setor financeiro - e os paraísos fiscais continuam a ser os seus principais destinos ${ }^{7}$. No entanto, a partir do processo de estabilização e privatizações, em 1994, a indústria de transformação também passou a internacionalizar suas operações de maneira mais significativa, utilizando o investi-

Gráfico 2 - Desembolsos do BNDES entre 2000 e 2010 (R\$ bilhões)

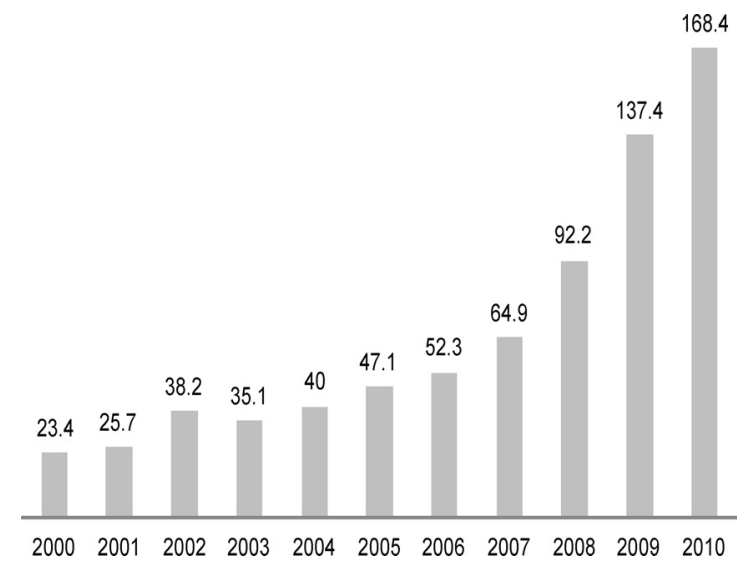

Fonte: BNDES (2007; 2010b). 
${ }^{8}$ Detalhes da política de internacionalização estão na apresentação do então presidente do BNDES, Demian Fiocca (2006) mento direto no exterior como uma estratégia para ganhar competitividade em um mundo mais liberalizado e globalizado. A criação do Mercosul favoreceu esse processo, consolidando um mercado favorável à expansão operacional de empresas brasileiras do setor industrial. Desde os anos 1990, além de empresas estatais remanescentes com forte atuação internacional, como Petrobras e Eletrobrás, o Brasil conta com transnacionais privadas capazes de competir e operar globalmente, como AmBev, Vale, Embraer e Gerdau (Corrêa \& Lima 2008).

Nessa primeira onda de firmas transnacionais privadas brasileiras, houve em comum o fato de que as iniciativas de internacionalização decorreram mais de decisões das próprias empresas do que de políticas governamentais. Embora o governo tenha participado de alguns casos, como Embraer e Vale, refletindo o passado estatal dessas empresas, a internacionalização de firmas como Gerdau e AmBev foram antes soluções de mercado, derivadas do poder de expansão de firmas altamente competitivas em seus segmentos, cuja boa capacidade financeira, conhecimento de mercado e pleno domínio tecnológico faziam da inserção internacional um caminho natural a seguir - ainda que o ambiente macroeconômico do Brasil não fosse o mais favorável (Alem \& Cavalcanti 2005). Não existia, desse modo, uma política pública destinada a impulsionar a internacionalização produtiva de capital nacional durante o governo FHC e nos primeiros anos do governo Lula. O número reduzido de empresas privadas com operações no exterior no período era um indício dessa orientação.

No entanto, a política do governo brasileiro começou a mudar no final do primeiro mandato de Lula, em 2005. Sob os argumentos de aumentar as exportações, incrementar a competitividade interna e externa das empresas brasileiras e promover o desenvolvimento econômico sustentado, o BNDES ficou encarregado de acrescentar à política industrial do país ações diretas de apoio à internacionalização de empresas de capital nacional. Assim, o governo brasileiro passou a atuar não apenas por meio de ações indiretas, como liberalização de exportação de capitais e proteção via acordos internacionais, assistência técnica e seguros, mas também por meio de financiamento público a juros subsidiados e compra de participação acionária pela BNDES Participações (BNDESPAR), subsidiária de gestão de participações do banco ${ }^{8}$. Formalmente, o banco já podia emprestar para investimentos diretos brasileiros no exterior desde 2002, quando uma alteração em seu Estatuto Social passou a autorizar esse tipo de operação. Mas foi em julho de 2005 que sua diretoria aprovou uma resolução em que se estabeleceram as normas para o financiamento de IDE. Em setembro de 2005, concretizou-se a primeira operação, com a compra da Swift argentina pela JBS-Friboi. A partir de então, o Estado brasileiro deixou de ser indiferente ou um mero regulador em relação à internacionalização de capitais nacionais produtivos e passou a operar como um indutor desses investimentos, tornando-se ator decisivo na criação de empresas "campeãs mundiais", segundo a definição do atual presidente do BNDES, Luciano Coutinho (Almeida 2009, p. 41). Até 2005, o grupo JBS-Friboi não contava com nenhuma operação no exterior. Hoje, é o maior frigorífico do mundo e a empresa mais internacionalizada do Brasil ${ }^{9}$. Sem o auxílio governamental, dificilmente teria alcançado essa posição. O Estado, agora, tinha uma política ativa para a internacionalização de empresas.

\section{V - Internacionalização de empresas privadas no governo Lula}

${ }^{9}$ O grau de internacionalização de empresas brasileiras utilizado neste trabalho é medido por
Esta análise supõe que o recente processo de internacionalização produtiva de empresas privadas induzido pelo Estado reflete características institucionais mais gerais e duradouras da economia brasileira, como delineadas pela literatura sobre variedades de capitalismo. O Brasil apresenta uma estrutura de 
Fundação Dom Cabral (2011), cujo "índice de transnacionalidade" pondera receitas, ativos e funcionários no exterior. representação coletiva de interesses empresariais fragmentada e complexa, formada por entidades pluralistas e corporativistas, que atuam em diversas áreas das políticas públicas (Diniz 2010a; 2010b). No entanto, a política industrial vertical do governo federal, sob a qual se deram os casos de internacionalização na gestão Lula, não conta com uma arena de negociações coletivas capaz de coordenar politicamente os incentivos públicos a empresas privadas. Operada pelo BNDES, a política industrial vertical não se pauta por acordos coletivos entre Estado e empresariado, pelos quais se estabeleceriam metas e contrapartidas intra e intersetoriais com o propósito comum de aumentar a produtividade total da economia no longo prazo, proporcionando ganhos mútuos a agentes privados e, ao mesmo tempo, garantindo os benefícios públicos da política de incentivo à indústria. A falta desses elementos de concertação distancia a política industrial brasileira daquelas próprias de economias coordenadas de mercado, nas quais instrumentos de acordos coletivos se fazem presentes e o horizonte temporal das decisões de incentivo ao setor privado é maior. Também não se pode afirmar que existe similaridade com políticas industriais de economias liberais, cujo foco recai sobre direitos de propriedades e compras governamentais, e não subsídios públicos, como ocorre no Brasil (Schneider 2008; Delgado et al., 2010).

Consideradas essas variáveis institucionais, o argumento deste artigo é que o processo de internacionalização de empresas condicionou-se por demandas de curto prazo do empresariado privado por recursos da política industrial. Subjacente a essa hipótese está a concepção de que a ausência de coordenação política de longo prazo reduz o horizonte temporal das decisões de incentivo à indústria do governo brasileiro. Sem mecanismos de acordos coletivos entre Estado e empresariado capazes de pautar a alocação de recursos públicos, a política industrial vertical torna-se propensa a apoiar projetos de investimentos viáveis no curto prazo, ficando sujeita a demandas imediatas provenientes de grupos econômicos privados. A concentração de casos de internacionalização em setores intensivos em trabalho e recursos naturais decorre, desse modo, do fato de as demandas empresariais por apoio governamental a projetos de investimentos diretos no exterior originarem-se nesses setores. Por tratar-se dos setores mais competitivos da economia brasileira, são mais propensos a apresentar projetos bem estruturados no curto prazo do que setores menos competitivos, como os intensivos em tecnologia, cujos projetos de investimentos dependeriam de um prazo mais longo para tornarem-se viáveis.

Assim, a despeito da orientação inicial dos formuladores da política industrial de privilegiar o desenvolvimento de setores intensivos em tecnologia, prevaleceu, na fase de execução do programa de expansão do investimento direto brasileiro ao exterior, o apoio a setores já competitivos. Não há evidências para se afirmar que o movimento de internacionalização de empresas no governo Lula resultou de uma disputa entre diferentes setores da economia por aportes financeiros do BNDES, da qual alguns saíram "vencedores" e outros "perdedores", refletindo, supostamente, distintos níveis de influência política. Não houve demanda de setores intensivos em tecnologia por financiamento público para internacionalização produtiva. Nos eventos em análise, a arena da política industrial foi menos conflituosa e mais path dependent, no sentido de que se tratou de um processo político pautado por tempo e sequência. Com efeito, o argumento de que a preferência por projetos viáveis no curto prazo favoreceu setores já competitivos remete à importância do tempo como condicionante dos resultados de políticas públicas, na medida em que limita as opções dos agentes estatais e realimenta escolhas anteriores (Pierson 2000; 2004; Page 2006). No processo de internacionalização, o fato de apenas setores competitivos demandarem apoio governamental mostrou-se determinante para delimitar as alternativas dos tomadores de decisões estatais, desencadeando um 
Tabela 2 - Apoio do BNDES à JBS-Friboi entre 2005 e 2011

\begin{tabular}{llcc}
\hline Data & Tipo & Operação & Valor (R\$) \\
\hline 01 ago 2005 & Financiamento & Swift Armour & 187000000,00 \\
28 jun 2007 & Compra de ações & Swift Foods & 1463552345,17 \\
18 mar 2008 & Compra de ações & Smithfield e Tasman & 1109267813,00 \\
29 dez 2009 & Debêntures & Pilgrims Pride & 3479600000,00 \\
17 mar 2010 & Financiamento & Capital de giro & 200000000,00 \\
18 maio 2011 & Debêntures & Aumento do capital & 3477567913,60 \\
& & social & \\
Total & & & 9916988071,77 \\
\hline
\end{tabular}

Fonte: $\mathrm{O}$ autor.

processo de self-reinforcement (retroalimentação) do padrão tecnológico da indústria brasileira. Ou seja, quanto mais competitiva a empresa, mais recursos do BNDES é capaz de angariar para se internacionalizar, contradizendo, nos resultados, a alegação de que o bem público fundamental proporcionado por uma política industrial seja o desenvolvimento de setores pouco competitivos da economia.

Nos casos estudados a seguir, mostra-se como, por razões concorrenciais prementes, empresas privadas demandaram recursos governamentais para se internacionalizar. Enfatize-se que o governo federal utilizou como instrumento de apoio às empresas não apenas financiamento, mas também de compra de participação acionária via BNDESPAR, subsidiária do BNDES, em consonância com um fenômeno mais geral da economia brasileira de companhias privadas contarem com participação estatal - ou paraestatal, no caso de fundos de pensão de servidores públicos - em seu capital social (Lazzarini 2011). Como corolário, pode-se dizer que a política de investir em grandes grupos econômicos de setores já competitivos vai ao encontro dessa estratégia, por se tratar de empresas mais propensas a dar retorno de curto prazo aos acionistas.

V.1. - O caso JBS-Friboi

O processo de internacionalização produtiva do frigorífico JBS-Friboi, atualmente líder do setor de proteína animal no mundo, com aproximadamente $45 \%$ das vendas de carne bovina, foi um dos mais relevantes no período que vai de meados da década passada até o final de 2010, sem que esteja totalmente finalizado. Com início das operações em 1953, a Friboi cresceu rapidamente durante as décadas seguintes, tornando-se um dos maiores frigoríficos brasileiros no final do século passado, embora não chegasse a figurar entre as principais firmas do setor no mundo. Além de carne bovina in natura, a empresa expandiu suas atividades para outros tipos de proteína animal, como aves e suínos, além de alimentos industrializados, tornando-se um grupo diversificado baseado em produtos intensivos em mão-de-obra e recursos naturais. Como ocorre em muitos grupos econômicos nacionais, o controle da empresa sempre foi familiar. Em 2005, iniciou-se um processo de modernização da governança corporativa, com transformação em sociedade anônima e, posteriormente, abertura de capital, mas o controle permaneceu com a família Batista Sobrinho, proprietária do grupo desde o princípio. Foi também a partir de 2005 que se iniciou a acelerada expansão internacional da empresa, que até aquele momento não contava com nenhuma planta produtiva fora do Brasil. O primeiro investimento direto no exterior foi a compra da Swift Armour, maior frigorífico argentino até então. O valor da operação foi de aproximadamente R\$ 300 
Quadro 2 - Histórico da JBS-Friboi, a partir de 2005

\begin{tabular}{llll}
\hline Ano & Empresa & País & Evento \\
\hline 2005 & JBS S.A. & Brasil & Tranformação em sociedade anônima \\
2006 & Swift Armour & Argentina & Aquisição \\
& Venado Tuerto & Argentina & Aquisição \\
2007 & Pontevedra & Agentina & Aquisição \\
& Bovespa & Brasil & Abertura de capital \\
& Berazategui & Argentina & Aquisição \\
& Colonia Caroya & Argentina & Aquisição \\
& SB Holdings & EUA & Aquisição \\
& Swift Foods & EUA & Aquisição \\
2008 & Inalca & Itália & Aquisição de 50\% \\
& Smithfield & EUA & Aquisição \\
& Tasman & Austrália & Aquisição \\
& Bertin & Brasil & Incorporação \\
& Pilgrims Pride & EUA & Aquisição de 64\% \\
\hline
\end{tabular}

Fonte: $\mathrm{O}$ autor.

${ }^{10}$ Dados sobre a trajetória da JBS-Friboi e sobre aportes do BNDES na empresa foram retirados, respectivamente, do sítio, de relatórios da administração da companhia e do site do BNDES, no qual o banco disponibiliza informações sobre os financiamentos concedidos a entes públicos e privados. Mantiveram-se os valores nominais das operações financeiras. milhões, dos quais R\$ 187 milhões foram financiados pelo BNDES. Foi, também, a primeira operação do banco de financiamento de compra no exterior. Para ilustrar a evolução da JBS-Friboi, o Quadro 2 relata os principais eventos relacionados à empresa desde $2005^{10}$.

A expansão internacional continuou nos anos seguintes, conforme ficou evidente no Quadro 2. Em 2006, a JBS-Friboi comprou mais dois frigoríficos na Argentina. Em 2007, a empresa abriu o capital na Bolsa de Valores de São Paulo, o que lhe proporcionou maior capacidade financeira para fazer novas aquisições. Nesse ano, depois de adquirir outros dois frigoríficos na Argentina e uma distribuidora de alimentos nos Estados Unidos, deu um grande salto em sua estratégica de investimentos no exterior ao adquirir a Swift Foods americana, o que transformou o frigorífico brasileiro em um dos maiores do mundo, com grande importância também para o processamento de aves e suínos. Essa aquisição contou com forte apoio do BNDES, que adquiriu participação acionária na JBS superior a $\mathrm{R} \$ 1,4$ bilhão, correspondente a aproximadamente $13 \%$ do capital da empresa. Ainda em 2007, a JBS adquiriu 50\% do capital da italiana Inalca, marcando o estabelecimento de operações do grupo também na Europa. O ano de 2008 também foi caracterizado por grandes aquisições e forte participação do BNDES nessas operações. Um aporte de $\mathrm{R} \$ 1,1$ bilhão da BNDESPAR permitiu a compra da americana Smithfiel e da australiana Tasman, ao mesmo tempo em que a participação do banco estatal na JBS subiu para 23\%. Em 2009, foi a vez de comprar 64\% da Pilgrim's Pride, gigante americana do setor de frangos. Dessa vez, o BNDES participou adquirindo mais de R \$ 3,5 bilhões em debêntures da JBS. Outro evento relevante, ocorrido em 2009, foi a incorporação do frigorífico brasileiro Bertin - que já havia sido apoiado pelo BNDES em operações de internacionalização - pela JBS. Em 2010, houve ainda a compra da australiana Tatiara Meat Company (TMC). Em suma, entre 2005 e 2010 a JBS-Friboi passou de empresa nacional para transformar-se em corporação transnacional, contando com o apoio decisivo do BNDES, cuja participação direta na empresa atualmente é de 17,02\%. Na Tabela 2, mostram-se os aportes do BNDES na empresa a partir de 2005. 
De acordo com Stal, Sereia e Silva (2010), a principal razão da demanda por recursos para internacionalização produtiva por parte da JBS-Friboi - e de outras empresas do setor frigorífico brasileiro, como Bertin, Marfrig, Sadia e Perdigão - foram barreiras sanitárias à importação de carnes aplicadas por alguns dos maiores mercados consumidores do produto a partir de 2005. Essas barreiras são rígidas principalmente nos Estados Unidos e na União Europeia, os mais rentáveis mercados do mundo, que utilizam restrições sanitárias não apenas como medidas de saúde pública, mas também como estratégia de disputas comerciais. Apesar de o Brasil ter muitas vantagens comparativas e competitivas na produção de carnes, barreiras sanitárias impostas às exportações de produtores nacionais prejudicam a rentabilidade do setor, levando os frigoríficos a buscarem alternativas de acesso a mercados estrangeiros. O investimento em plantas produtivas no exterior caracterizou uma solução concorrencial encontrada pela JBS-Friboi. A compra de empresas na Europa e nos Estados Unidos foi uma maneira de alcançar esses mercados produzindo diretamente em seus territórios, o que suprime barreiras sanitárias relacionadas ao comércio exterior. Da mesma forma, aquisições na Austrália e na Argentina ocorreram porque as restrições sanitárias às exportações de carnes desses países são menores do que as aplicadas ao Brasil, o que facilita o acesso aos mercados americano e europeu via exportações (idem).

\section{V.2. - O caso Fibria}

${ }^{11}$ Dados sobre composição acionária e participação de mercado foram extraídos do site e dos "Relatórios de Sustentabilidade" da Fibria, bem como do relatório setorial 2009/2010 da Associação Brasileira de Celulose e Papel (BRACELPA 2010).
O surgimento da Fibria Celulose S.A., em 2009, configurou outro caso importante na política de formação de grandes empresas transnacionais privadas brasileiras. A companhia resultou da fusão de duas das maiores empresas nacionais de papel e celulose: Votorantim Papel e Celulose (VCP) e Aracruz Celulose. A primeira empresa era uma subsidiária do grupo Votorantim, um dos principais grupos econômicos diversificados do Brasil, cujo controle pertence à família Ermírio de Moraes. Já o controle da Aracruz pertencia ao grupo Safra (20,5\%), com participação minoritária do grupo norueguês Lorentzen (12,4\%), BNDESPAR $(5,5 \%)$ e da própria VCP $(12,4 \%)$ (Vidal \& Hora 2011, p. 159). Ambas empresas já apresentavam elevado grau de internacionalização, com a maioria da produção voltada às exportações e atendimento a mercados de todos os continentes por meio de escritórios comerciais e centros de distribuição. Também eram produtoras de papel, mas, refletindo uma tendência do mercado brasileiro e a trajetória de elevação dos preços internacionais de commodities de recursos naturais, passaram gradativamente a concentrar-se apenas na produção de celulose (Gomes 2011). A Fibria nasce como uma empresa focada na produção de celulose. Atualmente, é um dos principais players globais do setor, figurando como líder mundial em vendas de pasta de celulose de fibra curta branqueada (BHKP). Segundo dados de 2009, concentra 38,9\% da produção brasileira total do produto, da qual exporta aproximadamente $90 \%$. Em 2010, o faturamento bruto foi de $\mathrm{R} \$ 7,05$ bilhões ${ }^{11}$.

O processo de formação da Fibria contou com apoio decisivo do BNDES, que viabilizou a operação comprando participação acionária por meio da BNDESPAR. Após negociações que se estenderam desde o segundo semestre de 2008, anunciou-se, em setembro de 2009, um acordo de recomposição acionária entre os controladores de Aracruz e VCP, dando início à nova empresa. Pelo acordo, a VCP adquiriu parte das participações dos grupos Safra e Lorentzen na Aracruz e passou a controlar 29,34\% da Fibria, caracterizando antes um caso de incorporação de uma empresa por outra do que fusão propriamente dita. O BNDES entrou na operação desembolsando R $\$ 2,6$ bilhões para adquirir parte do capital social da nova empresa. Acrescentados aos 5,5\% de participação que já tinha na Aracruz, a BNDESPAR passou a controlar $34,9 \%$ da companhia. Ou seja, o governo brasileiro, por meio da subsidiária do 
BNDES, tornou-se controlador majoritário da Fibria, tendo o grupo Votorantim como sócio minoritário. Desde então, sucessivos aumentos no capital social da empresa diminuíram a participação estatal, mas o controle ainda permanece com o governo. De acordos com dados atuais de composição societária, a BNDESPAR detém 30,42\% do controle da Fibria, ao passo que a Votorantim Industrial S.A. conta com $29,34 \%$ de participação.

O pano de fundo da tomada de decisão para a formação da Fibria foi a crise financeira internacional que eclodiu no segundo semestre de 2008, alterando substancialmente a conjuntura de mercado para empresas produtoras de celulose. A consequência mais imediata foi uma queda na demanda internacional do produto, rebaixando os preços praticados por firmas exportadoras, como VCP e Aracruz. Porém, embora tenha afetado os resultados operacionais de ambas as empresas e do setor como um todo, esse não foi o fator preponderante para a criação da Fibria. Além da queda dos preços da celulose no mercado internacional, a crise também desencadeou uma desvalorização expressiva do real em relação dólar, cuja cotação passou de $\mathrm{R}$ \$ 1,60, em agosto de 2008, para $\mathrm{R}$ \$2,40, em dezembro do mesmo ano. A variação cambial abrupta trouxe consequências adversas para empresas brasileiras, e uma das mais afetadas foi a Aracruz Celulose. A empresa tinha posições descobertas no mercado de derivativos, que, antes da crise, eram utilizados para minimizar efeitos negativos da valorização do real sobre as exportações e alavancar os resultados financeiros. Ou seja, a estratégia cambial da Aracruz apostava que o real continuaria a trajetória de valorização, mas a crise internacional de 2008 reverteu essa tendência e desvalorizou abruptamente a moeda brasileira. No final de 2008, a empresa anunciou perdas de US\$2,1 bilhões com derivativos, comprometendo seriamente seu balaço patrimonial.

Foi nesse cenário que o BNDES entrou na operação de criação da Fibria. Antes da crise, a VCP já demonstrava interesse em controlar a Aracruz. Havia um acordo entre os controladores para a fusão das duas empresas, mas não se previa a participação do banco estatal. Segundo Vidal e Hora (2011), as perdas da Aracruz com derivativos constituíram um fator decisivo para os grupos controladores demandarem apoio do BNDES para a formação da nova empresa. $\mathrm{O}$ aporte de R \$ 2,6 bilhões do governo federal foi uma maneira encontrada de viabilizar-se a incorporação da Aracruz pela VCP e facilitar a recuperação financeira de uma empresa que havia incorrido em grandes perdas cambiais, mas permanecia operacionalmente saudável. Sem o aporte, os controladores da Aracruz teriam dificuldades para renegociar a dívida contraída. Da mesma forma, a Votorantim - que também havia incorrido em perdas com derivativos em outras empresas do grupo - não estava disposta a levar a operação de fusão adiante, pois teria que desembolsar mais de $\mathrm{R} \$ 5,4$ bilhões, ultrapassando sua capacidade de endividamento. Com o aporte estatal desembolsou R\$ 2,7 bilhões, metade do valor. Assim, pautando-se pela demanda de grupos empresariais privados, o BNDES entrou na operação, assumindo o controle da empresa por meio da BNDESPAR e participando da formação de uma empresa transnacional brasileira de caráter global.

\section{VI - Conclusão}

O objetivo desta pesquisa foi analisar a economia política do recente processo de formação de empresas transnacionais privadas brasileiras. Iniciado em meados da década passada, na gestão Lula, contou com forte apoio da política industrial do governo federal, por meio do BNDES. Uma característica importante desse movimento foi a concentração dos incentivos governamentais em setores nos quais o Brasil já é competitivo, como os intensivos em recursos naturais, embora as diretrizes originalmente estabelecidas pela própria política 
industrial do governo Lula preconizassem o apoio a setores mais intensivos em tecnologia. Buscando desvendar a razão dessa contradição, argumentou-se que, dada a dificuldade de estabelecerem-se acordos de longo prazo entre Estado e setor privado, a política industrial brasileira pautou-se por demandas de curto prazo do empresariado nacional. Utilizando a abordagem institucional das variedades de capitalismo, que vincula resultados de políticas de desenvolvimento a diferentes arranjos institucionais das economias nacionais, mostrou-se como a ausência de mecanismos institucionais que permitam estabelecer acordos intra e inter-setoriais com o empresariado privado deixou a política de internacionalização de empresas sujeita a demandas de curto prazo de grupos econômicos nacionais. Assim, conclui-se que a concentração de apoio em setores já competitivos decorreu do fato de apenas esses setores terem sido capazes de apresentar projetos de investimentos viáveis no curto prazo, e não de uma suposta capacidade de influenciar politicamente os resultados da política industrial - e isso é path dependent.

Para embasar o argumento, apresentaram-se evidências em dois estudos de casos de formação de empresas transnacionais brasileiras. Neles, ficam claras as demandas de curto prazo do empresariado por recursos da política industrial. Em razão de pressões concorrenciais iminentes, grupos econômicos privados requisitaram apoio do BNDES para seus projetos de internacionalização, pautando o processo de formação de grandes empresas nacionais aspirantes à liderança mundial em seus setores. Um dos casos analisados foi a internacionalização da JBS-Friboi, atualmente líder mundial no setor de proteína animal, cuja necessidade de internacionalização decorreu das crescentes barreiras sanitárias impostas às exportações de carnes brasileiras nos Estados Unidos e na União Europeia. Outro caso foi a Fibria, cuja formação com participação do governo federal decorreu de um desequilíbrio patrimonial da Aracruz Celulose, em razão de uma dívida contraída abruptamente na crise internacional de 2008. Assim, baseada na análise de dois casos de segmentos econômicos diferentes, buscou-se identificar os condicionantes políticos da política industrial brasileira no processo de internacionalização de empresas nacionais, caracterizando-a como path dependent de demandas de curto prazo do empresariado, o que pode levar a resultados contraditórios àqueles delineados na fase de formulação.

Danilo Rocha (drocha@usp.br) é Mestre em Relações Internacionais pela Universidade de São Paulo (USP) e doutorando em Economia do Desenvolvimento pela mesma universidade.

\section{Referências}

Alem, A.; Cavalcanti, C. 2005. O BNDES e o apoio à internacionalização de empresas brasileiras: algumas reflexões. Revista do BNDES, 12(24), pp. 43-76.

Almeida, M. 2009. Desafios da política industrial brasileira no século XXI. Texto para discussão n. 1 452. Brasília: IPEA.

Bohle, D.; Greskovits, B. 2009. Varieties of Capitalism and Capitalism. European Journal of Sociology, 50(3), pp. 355-386.

Büthe, T.; Milner, H. 2008. The Politics of Foreign Direct Investment into Developing Countries: Increasing FDI through international trade agreements? American Journal of Political Science, 52(4), pp. 741-762.

Cardoso, F.H. 1972. Empresário industrial e desenvolvimento econômico no Brasil. São Paulo: Difusão Européia do Livro.

Corrêa, D.; Lima, G. 2008. O comportamento recente do investimento direto brasileiro no exterior em perspectiva. Revista de Economia Política, 28(2), pp. 249-268.

Delgado, I. 2008. Variedades de capitalismo e política industrial: o caso brasileiro em perspectiva comparada. In: XXI Jornadas de História Econômica. Buenos Aires.

Delgado, I.; Condé, E.; Ésther, A.; Salles, H. 2010. Variedades de capitalismo e política industrial nos EUA, Alemanha, Espanha, Coreia, Argentina, México e Brasil (1998-2008). Dados, 53(4), pp. 959-1 008.

Diniz, E.; Boschi R. 2004. Empresários, interesses e mercado. Dilemas do desenvolvimento no Brasil. Belo Horizonte: Editora UFMG.

Diniz, E. 2010a. Empresariado industrial, representação de interesses e ação política: trajetória histórica e novas configurações. Política \& Sociedade, 9(17), pp. 101-139.

.2010b. Estado, variedades de capitalismo e desenvolvimento em países emergentes. Desenvolvimento em Debate, 1(1), pp. 7-27. 
Dunning, J.1988. Explaining International Production. London: Unwin Hyman.

Fiocca, D. 2006. As novas multinacionais brasileiras. In As novas multinacionais brasileiras. Rio de Janeiro, Firjan.

Flynn, M. 2007. Between Sub-imperialism and Globalization: A case study in the internationalization of Brazilian capital. Latin American Perspectives, 34(9), pp. 9-27.

Furtado, C. 1965. Obstáculos políticos ao crescimento econômico no Brasil. Revista Civilização Brasileira, 1(1), pp. 129-145.

Gammeltoft, P. 2008. Emerging Multinationals: Outward FDI from the BRICS Countries. International Journal of Technology and Globalization, 4(1), pp. 5-22.

Gammeltoft, P.; Pradhan, J.; Goldstein, A. 2010. Emerging Multinationals: Home and host country determinants and outcomes. International Journal of Emerging Markets, 5(3/4), pp. 254-265.

Gomes, I. 2011. Segmento brasileiro de polpa celulósica: evolução, competitividade e inovação. São Paulo. Tese (Doutorado em Economia). Universidade de São Paulo.

Hall, P.A.; Soskice, D. 2001. Varieties of Capitalism: The institutional foundations of comparative advantage. Oxford: Oxford University Press.

Hennart, J. 2001. Theories of the Multinational Enterprise. In: Rugman, A.; Brewer, T., eds. The Oxford Handbook of International Business. Oxford: Oxford University Press.

Hiratuka, C.; Sarti, F. 2011. Investimento direto e internacionalização de empresas no período recente. Texto para discussão $n$. 1 610. Brasília: IPEA.

Jackson, G.; Deeg, R. 2006. How Many Varieties of Capitalism? Comparing the comparative institutional analyses of capitalist diversity. MPIfG Discussion Paper, N. 06/2. Disponível em: http://ssrn.com/abstract = 896384. Acesso em: 25 ago 2014 .

Lazzarini, S. 2011. Capitalismo de Laços: os donos do Brasil e suas conexões. Rio de Janeiro: Editora Campus.

Luce, M. 2007. O subimperialismo brasileiro revisitado: a política de integração regional do governo Lula. Porto Alegre. Dissertação (Mestrado em Relações Internacionais). Universidade Federal do Rio Grande do Sul.

Mancuso, W. 2004. O lobby da indústria no Congresso Nacional: empresariado e política no Brasil contemporâneo. Dados, 47(3), pp. 505-547.

2007. O empresariado como ator político no Brasil: balanço da literatura e agenda de pesquisa. Revista de Sociologia e Política, 28, pp. 131-262.

Mancuso, W.; Oliveira, A. 2006. Abertura econômica, empresariado e política: os planos doméstico e internacional. Lua Nova, 69, pp. 147-172.

Marini, R.M. 1972. Brazilian Subimperialism. Monthly Review, 23(9), pp. 14-24.

Oliveira, A. 2003. O papel da coalizão empresarial brasileira e as negociações da Alca. São Paulo. Tese (Doutorado em Ciência Política). Universidade de São Paulo.

Page, S. 2006. Path Dependence. Quarterly Journal of Political Science, 1(1), pp. 87-115.

Pierson, P. 2000. Increasing Returns, Path Dependence, and the Study of Politics. American Political Science Review, 94(2), pp. 251-267.

. 2004. Politics in Time: History, Institutions, and Social Analysis. Princeton: Princeton University Press.

Power, T.; Doctor, M. 2002. The Resilience of Corporatism: Continuity and change in Brazilian corporatist structures. Working Paper N. CBS-20-01, University of Oxford.

Prochnik, V. 2009. Por que é baixo o investimento direto das firmas brasileiras no exterior? Revista de Economia do Mackenzie, 6(1), pp. 11-40.

Rabelo, T.; Simões, A. 2010. O papel do BNDES na alocação de recursos: avaliação do custo fiscal do empréstimo de R 100 bilhões concedidos pela União em 2009. Revista do BNDES, 33, pp. 5-54.

Robinson, W. 2004. A Theory of Global Capitalism: Production, class and State in a transnational world. Baltimore: John Hopkins University Press.

Robinson, J.A. 2009. Industrial Policy and Development: A Political Economy perspective. In: ABCDE - Annual World Bank Conference on Development Economics. Seoul.

Schneider, B.R. 2002. Some Consequences of Business Organization for Development and Democracy in Latin America. In: Workshop "Changing Nature of Business-State Relations in Brazil: Strategies of Foreign and Domestic Capital. University of Oxford.

2004. Business Politics and the State in Twentieth-Century Latin America. New York: Cambridge University Press. 2008. Comparing Capitalisms: Liberal, coordinated, network, and hierarchical varieties. Digit. Disponível em: www.ideiad.com.br/seminariointernacional/arquivo1.pdf. Acesso em: 25 ago 2014. . 2009. Hierarchical market economies and varieties of capitalism in Latin America. Journal of Latin American Studies, 41(3), pp. 553-575.

Schneider, B.R.; Soskice, D. 2009. Inequality in Developed Countries and Latin America: Coordinated, liberal, and hierarchical systems. Economy and Society, 38(1), pp. 17-52.

Sklair, L. 2002a. Democracy and the Transnational Capitalist Class. Annals of the American Academy of Political and Social Science, 581, pp. 144-157.

.2002b. The Transnational Capitalist Class and Global Politics: Deconstructing the corporate-State connection. International Political Science Review, 23(2), pp. 159-174.

Stal, E.; Sereia, V.; Silva, R. 2010. Estratégias de internacionalização do setor agroindustrial brasileiro de carnes: exportação ou investimento direto no exterior? Future Studies Research Journal, 2(2), pp. 132-161.

Suzigan, W.; Furtado, J. 2006. Política industrial e desenvolvimento. Revista de Economia Política, 26(2), pp. 163-185. 
2010. Instituições e políticas industriais e tecnológicas: reflexões a partir da experiência Brasileira. Estudos Econômicos, 40(1), pp. 7-41.

Vidal, A.; Hora, A. 2011. A atuação do BNDES nos setores de florestas plantadas, painéis de madeira, celulose e papéis: o período 2001-2010. BNDES Setorial - Papel e Celulose, 34, pp. 133-172.

\section{Outras fontes}

Banco Central do Brasil. 2006. Relatório de Capitais Brasileiros no Exterior (CBE) - 2001 a 2006. Disponível em: http://www4.bcb.gov.br/rex/CBE/Port/ResultadoCBE2006.pdf. Acesso em: 26 ago 2014.

2008. Boletim do BC - Relatório anual sobre finanças públicas. Disponível em: www.bcb.gov.br/pec/boletim/banual2008/rel2008cap4p.pdf. Acesso em: 26 ago 2014.

2010. Boletim do BC - Relatório anual sobre finanças públicas. Disponível em: www.bcb.gov.br/pec/boletim/banual2010/rel2010cap4p.pdf. Acesso em: 26 ago 2014.

BNDES. 2007. Relatório anual 2007. Disponível em: www.bndes.gov.br/SiteBNDES/export/sites/default/bndes_pt/Galerias/Arquivos/empresa/RelAnual/ra2007/relatorio_anual2007.pdf. Acesso em: 26 ago 2014.

2010a. Demonstrações contábeis 2010. Disponível em: http://www.bndes.gov.br/SiteBNDES/export/sites/default/bndes_pt/Galerias/Arquivos/empresa/RelAnual/ra2010/DemonstracoesContabeis2010.pdf. Acesso em: 26 ago 2014.

2010b. Relatório anual 2010. Disponível em: www.bndes.gov.br/SiteBNDES/export/sites/default/bndes_pt/Galerias/Arquivos/empresa/RelAnual/ra2010/relatorio_anual2010.pdf. Acesso em: 26 ago 2014.

Bracelpa. 2010. Relatório estatístico anual 2009/2010. Disponível em: www.bracelpa.org.br/bra2/sites/default/files/estatisticas/rel2009.pdf. Acesso em: 11/07/2013.

Brasil. 2004. Diretrizes de política industrial, tecnológica e de comércio exterior. Disponível em: www.inovacao.unicamp.br/politicact/diretrizes-pi-031212.pdf. Acesso em: 26 ago 2014.

2008. Política de desenvolvimento produtivo. Inovar para sustentar o crescimento. Disponível em: www.desenvolvimento.gov.br/pdp/arquivos/destswf1212175349.pdf. Acesso em: 26 ago 2014.

Fundação Dom Cabral. 2011. Ranking das transnacionais brasileiras: crescimento e gestão sustentável no exterior. $6^{\mathrm{a}}$ ed. "Relatórios FDC". Belo Horizonte.

UNCTAD. 2011a. Handbook of Statistics 2011. Genebra: United Nations Publication.

2011b. World Investment Report 2011: Non-equity modes of international production and development. Genebra: United Nations Publication.

. 2012. UNCTADStat. Banco de dados sobre investimento, comércio e desenvolvimento. Disponível em: http://unctad.org/en/pages/Statistics.aspx. Acesso em: 26 ago 2014.

\section{ABSTRACT}

This paper analyzes the political economy of the internationalization process of Brazilian private companies occurred during Lula administration (2003-2010). Since 2005, there was an expansion of Brazilian foreign direct investment abroad, as a result of a federal government policy intended to form large corporations able to compete internationally. Major mergers, acquisitions and investment projects abroad were financed by public funds under the industrial policy operated by National Bank of Economic and Social Development (BNDES), the main state bank to support the private sector in the country. An important feature of this movement was the focus on sectors in which Brazil is already competitive, as the labor and natural resources intensives sectors, in conflict with guidelines established by the same industrial policy of the Lula government, which advocated the support of more technology intensive industries. From the empirical analysis of internationalization cases, it is argued that this occurred because the internationalization policy was guided by short-term demands of private economic groups. Using the institutional approach of "varieties of capitalism", it is concluded that the action of the BNDES was path dependent, in the sense that depended on projects of immediate viability. It is inferred from the result that wider institutional characteristics of the Brazilian economy leave the industrial policy of the federal government subject to short-term demands of the private sector.

KEYWORDS: firm's internationalization; industrial policy; BNDES; varieties of capitalism; entrepreneurs. 